\title{
Are There Differences in Performance, Metabolism, and Quadriceps Muscle Activity in Black African and Caucasian Athletes during Brief Intermittent and Intense Exercise?
}

\author{
A. TEMFEMO ${ }^{1}$, C. LAPARADIS ${ }^{2}$, D. BISHOP ${ }^{3}$, A. MERZOUK $^{1}$, and S. AHMAIDI ${ }^{1}$ \\ ${ }^{1}$ EA 3300 "APS et Conduites Motrices: Adaptations, Réadaptations", Université de Picardie Jules Verne, Faculté des Sciences du \\ Sport, F-80025 Amiens Cedex, France; 2Department of Physical Education and Sport Science, Democritus University of Thrace, \\ Komotini, Greece; and ${ }^{3}$ Team Sport Research Group, School of Human Movement and Exercise Science, The University of Western \\ Australia, Crawley, WA 6009, Australia
}

\begin{abstract}
The purpose of the present study was to determine whether there are any differences in power output (PO) and/or quadriceps muscle (Quad) activity between black African and Caucasian football players during a force-velocity (fv) exercise test, which consisted of performing maximal 6-s sprints against an increasing load. Each subject started the test with a load of 2 $\mathrm{kg}$ and then recovered for $5 \mathrm{~min}$ before repeating the same test with a load increased by $2 \mathrm{~kg}$. When the pedal frequency did not exceed $130 \mathrm{rev} \cdot \mathrm{min}^{-1}$, the load was increased by only $1 \mathrm{~kg}$. Each subject attained the load corresponding to his maximal power if an additional increase in load $(+1 \mathrm{~kg})$ induced a power decrease. Nine black Africans (mean age $24.2 \pm 3.3$ years) and nine Caucasians (24.7 \pm 4.2 years) (matched for stature and
\end{abstract}

aerobic fitness) participated in the fv exercise test. During the test, $\mathrm{PO}$, blood lactate, and the quadriceps electromyography (EMG) root mean square (Quad RMS) were assessed. Higher blood lactate was observed in Caucasians than in black Africans for POs over the load range from $4 \mathrm{~kg}$ up to the maximal power. However, $\mathrm{PO}$ and Quad RMS values were similar in Caucasians and black Africans. They also had similar lean leg volume (LLV) and consequently produced similar PO/LLV and Quad RMS/LLV values. Overall, our results suggest that Caucasians and black Africans matched for stature, $\dot{\mathrm{V}}_{2 \text { max }}$, and training background have similar PO and Quad RMS values, but different blood lactate concentrations during brief, intermittent, intense exercise performed on a cycloergometer.

Key words: force-velocity test, black and Caucasian subjects, power output, EMG.

\begin{abstract}
Several studies have compared black and Caucasian responses to intense, continuous exercise $[4,8,26]$. Bosch et al. [4] reported a higher fractional utilisation of $\dot{\mathrm{V}}_{2 \text { max }}$ for the same lactate accumulation in black South Africans compared with Caucasian South African marathon runners. The findings of Coetzer et al. [8] indicated greater resistance to fatigue in black South African runners than in their Caucasian counterparts, despite comparable $\dot{\mathrm{VO}}_{2 \text { max }}$ values. It should be noted that the test used by Coetzer et al. [8] to quantify resistance to fatigue involved repeated isometric contractions of the quadriceps muscles. Nevertheless, Coetzer et al. [8] also reported that the plasma lactate concentration was significantly lower in the black African runners at two submaximal running workloads, despite an $\mathrm{O}_{2}$ consumption similar to that seen in the Caucasian runners. Lower lactate accumulation has also consistently been reported in studies of black African runners [4, 31] and elite Kenyan runners [26], compared
\end{abstract}

with Caucasian runners.

In contrast to the many studies involving continuous exercise, there are few comparisons of exercise performance between black and Caucasian subjects during brief intense bouts of exercise [6]. This is surprising, since intermittent exercise (including repeated periods of maximal or all-out effort with varying loads) constitutes the principal physical activity for many people [12]. In particular, repeated, brief, intense efforts are common in team sports such as football and soccer, in which both black and Caucasian athletes participate.

Ama et al. [1] reported a higher proportion of type IIa muscle fibres in black Africans than in Caucasians, though there were no significant differences between the two racial groups in terms of type IIb fibre proportion or fibre area (I, IIa, and IIb). These authors also observed higher enzyme activity values for the phosphagenic and glycolytic metabolic pathways in black Africans com- 


\section{A. TEMFEMO et al.}

pared with Caucasians. Several authors have reported that muscle fibre type proportion $[17,28]$ and the capacity of the anaerobic energy pathways [17] are all associated with muscular power output. It could therefore be hypothesised that black African subjects might perform better than Caucasian subjects during brief, intense exercise. However, this hypothesis has not been assessed during brief intermittent intense bouts of exercise, such as the force-velocity (fv) exercise test performed on a cycloergometer [21, 29].

Furthermore, it has been reported that myoelectrical activity is positively correlated with both the proportion of type II muscle fibre [13] and the workload performed during exercise [3]. However, muscle activity during high-intensity performance has not been extensively studied in black and Caucasian subjects. Given that black Africans reportedly have a higher proportion of type IIa fibres than Caucasians [1], this suggests that myoelectrical activity during brief intense exercise could also be higher, though this has not been investigated. Based on these observations, the present study's second objective was to compare quadriceps EMG activity during the fv exercise test in black Africans and Caucasians.

\section{METHODS}

All tests were performed in two sessions separated by 3 days. The first session was used to perform anthropometric measurements and the maximal exercise test. During the second session, performance data, electromyography, and physiological parameters were collected during the $\mathrm{fv}$ exercise test.

Subjects. Nine black Africans from central African countries without sickle cell trait $(24.2 \pm 3.3$ years $)$, and 9 Caucasians $(24.7 \pm 4.2$ years) participated in this study. The experimental procedures complied with the ethical standards of the 1975 Helsinki Declaration. All subjects were football players training $6-8 \mathrm{~h}$ per week and who have competed in regional level competition for more than six years. Each subject was informed of the procedures and possible risks of the study before giving written consent to participate in the study. The subjects were asked to refrain from doing intense exercise two days before both the maximal exercise testing and the fv exercise test. All tests were performed in a laboratory at $220^{\circ} \mathrm{C}$ from 3 to 6 p.m.

Anthropometric characteristics measurements. All measurements were taken by the same observer following the techniques established by the International Biological Programme [30]. Body mass (BM), standing height (Ht), and body mass index $\left(\mathrm{BM}\right.$ in $\mathrm{kg} / \mathrm{Ht}$ in $\left.\mathrm{m}^{2}\right)$ were determined for each subject. The percentage of body fat (\%BF) was calculated using the Fernindez et al. [11] formula in men, where \%BF is 64.813-1,084.43 (1/BMI) in Caucasians and $65.832-1,146.108$ (1/BMI) in black African-
Americans. Lean body mass (LBM) was determined by subtracting the fat body mass from the total body mass. Lean leg volume (LLV) was assessed by anthropometry [16]. The technique consists of partitioning the leg volume into six segments, which are similar to truncated cones. This method has been validated for adults [16]. Also, skinfold measurements of the rectus femoris (RF), vastus lateralis (VL), and vastus medialis (VM) of the right thigh were taken using the Harpenden Skinfold Caliper (Baty International, Sussex RHI5 9LB, England) over the locations (marked using a pen with water-soluble ink) that were used for the EMG recordings.

Maximal exercise test. Aerobic fitness was assessed during the maximal exercise test on the cycle ergometer (824 Monark-Crescent, AB, Varberg, Sweden) with maximal oxygen uptake $\left(\dot{\mathrm{VO}}_{2 \text { max }}\right)$, maximal aerobic power output (MAP), and maximal heart rate $\left(\mathrm{HR}_{\max }\right)$ measurements. Oxygen uptake was measured using an open circuit technique with the CPX system (Medical Graphics Corporation, St. Paul, Minn., USA.), and heart rate (HR) was continuously recorded with an HR monitor (Polar Accurex Plus, Polar Electro, Kemple, Finland). The maximal exercise test protocol was the same for all subjects and consisted of 2 min warm-up cycling at $1 \mathrm{~kg}$, after which the work load was increased by $0.5 \mathrm{~kg}$ every $1 \mathrm{~min}$ until volitional exhaustion. The frequency was fixed at 60 rev. $\mathrm{min}^{-1}$. To ensure that $\mathrm{V}_{2} \mathrm{O}_{\text {max }}$ was reached, the following criteria had to be met: (a) stability of $\mathrm{V}_{2}$ in spite of the increase in exercise load, (b) respiratory exchange ratio greater than 1.10 , (c) attainment of age-predicted $\mathrm{HR}_{\text {max }}$, and (d) inability of the subjects to maintain the frequency at $60 \mathrm{rev} \cdot \mathrm{min}^{-1}$ in spite of verbal encouragement. The results of this test enabled us to match subjects for aerobic fitness before participating in the fv exercise test.

Force-velocity exercise test. Three days after the maximal exercise testing, each subject was requested to report to the laboratory for the fv exercise test. This test was also carried out on a friction-loaded, cycle ergometer (824 Monark-Crescent, AB, Varberg, Sweden). The FV test consisted of performing a maximal sprint against an increasing load. The duration of each sprint was fixed at $6 \mathrm{~s}$, the maximal time for a subject to attain his maximal velocity after the starting signal. All subjects started the test against a load of $2 \mathrm{~kg}$ and then recovered for $5 \mathrm{~min}$ before repeating the same exercise against a load increased by 2 $\mathrm{kg}$. When the frequency was under $130 \mathrm{rev} \cdot \mathrm{min}^{-1}$, the load was increased by only $1 \mathrm{~kg}$ to obtain a peak power output as precisely as possible. It was assumed that the subject attained the load $\left(\mathrm{F}_{\mathrm{P} \max }\right)$ corresponding to his maximal power if an additional increase in load $\left(\mathrm{F}_{\mathrm{P} \max }+1 \mathrm{~kg}\right)$ induced a power decrease. As previously described [21], an automatic system was used to determine the maximal velocity (v) for each load and to calculate the fv relations. The accuracy of the frequency measurement was $\pm 3.3 \mathrm{~ms}$. PO was calculated as the product of load and velocity $(\mathrm{F} \times \mathrm{v})$. 
During this test, the subjects remained in a sitting position for the sprints and all the recovery periods; their feet were fixed to the pedals with toe clips.

EMG measurements. Surface electromyography (EMG) signals have been extensively used to noninvasively characterize the electrophysiological fatigue processes during dynamic contractions $[5,15]$. During the fv exercise test, quadriceps muscle activity was determined for all subjects by the assessment of surface electromyogram (SEMG) from the rectus femoris (RF), vastus lateralis (VL), and vastus medialis (VM) muscles. The skin was cleaned and abraded first. Beckman (type: $0.9 \mathrm{~cm}$ diameter, physio-systems, Noisy-le-Grand) bipolar surface electrodes, spaced by $2 \mathrm{~cm}$ distance, were placed over the centre of the belly of each of the three muscles of the right leg. The ground electrode was placed at the right wrist. The SEMG signals were conditioned and stored on magnetic tape (TEAC R-71, TEAC Corp., Tokyo, Japan), after differential amplification with bandwidth ranging from $2 \mathrm{~Hz}$ to $2 \mathrm{kHz}$ along with the output signal from the dynamometer. The SEMG signals were sampled by a spectrum analyser (model 3582A, Hewlett-Packard, Les Ulis) at 1024 Hz. The power spectral density (PSD) was calculated from 0.5 -s time intervals and was defined by 256 points in amplitude and phase in the $2-514 \mathrm{~Hz}$ bandwidth. Each PSD was then computed and divided into 10 bands, the bandwidth being $24 \mathrm{~Hz}$, except for the highest band (56 $\mathrm{Hz}$ ). The SEMG signals were analysed using acquisition and spectrum analyzer software (Spatol, Divergent, Compiègne, France) and a data-computing software (Calvise, Divergent, Compiègne, France). The Calvise software allows the transformation of PSD into four parameters, among which is the root mean square (RMS). For each subject, the RMS was determined for each muscle workload. The RMS of quadriceps muscle (Quad RMS) was then considered as the sum of the RMS of RF, VL, and VM [25].

Blood lactate concentration assessment, heart rate, and skin temperature. To determine the blood lactate concentration of each subject during the fv exercise test, we collected blood samples using microcapillary tubes at rest $\left(\mathrm{R}_{0}\right)$ and $3 \mathrm{~min}$ after each sprint by micropunctures at the fingertips. Blood lactate concentration was then analyzed at the end of the fv exercise test using a Miniphotometer Plus LP 20 (Monitor-8, Anglet-France). During the fv exercise test, the quadriceps skin temperature $\left(T_{\text {sk }}\right)$ and the heart rate (HR) were recorded continuously. A heart rate monitor (Polar Accurex Plus, Polar electro, Kemple, Finland) was used to monitor and store HR during the fv exercise test. To accurately assess peak HR response to the sprints, HR was measured at every second and was averaged over $5 \mathrm{~s}$. The highest averaged value was considered as the peak HR. The $\mathrm{T}_{\mathrm{sk}}$ was recorded using a thermometer TH-5 (Physitemp Instruments, Inc., Clifton, NJ, USA). The probe was applied to the RF muscle. The $\mathrm{T}_{\text {sk }}$ values were determined at rest $\left(\mathrm{R}_{0}\right)$ and after each sprint. The highest value of the $\mathrm{T}_{\text {sk }}$ obtained during the recovery period (from $0 \mathrm{~min}$ to $4 \mathrm{~min} 30 \mathrm{~s}$ ) was considered as the peak $\mathrm{T}_{\text {sk }}$ for each sprint.

Statistical analysis. Statistical comparisons were performed using the StatView software (Abacus Concepts, Berkeley, California, USA). The results are presented as mean \pm SD. A comparison of anthropometric characteristics (standing height, BM, BMI, \%Fat, LBM, LLV, and Skinfold), maximal aerobic performance $\left(\mathrm{HR}_{\max }\right.$, $\mathrm{V}_{2}$ max , and MAP) in black Africans and Caucasians were performed using the Student's $t$-test when the normality distribution (Kolmogorov-Smirnov test) and the equality of variance of compared variables were verified. The comparison of variables obtained during the fv exercise test in both racial groups ( $\mathrm{HR}, \mathrm{T}_{\mathrm{sk}}$, blood lactate concentration, PO, and RMS) was performed by a two-way analysis of variance (racial groups, load) with repeated measures. When significant $F$-ratios were found, the means were compared using a post hoc Mann-Whitney rank sum test. The differences were considered significant at $p<0.05$.

\section{RESULTS}

\section{Anthropometric characteristics and aerobic fitness performance}

The black African and Caucasian groups studied here did not differ significantly in terms of mean age, mass, height, body mass index (BMI), percentage of fat body mass (\%Fat), lean body mass (LBM), lean leg volume (LLV), and skinfold thickness of the rectus femoris (RF), vastus lateralis (VL), and vastus medialis (VM). Aerobic fitness indices did not differ between the groups. Maximal oxygen uptake $\left(\dot{\mathrm{V}} \mathrm{O}_{2 \text { max }}\right)$, maximal aerobic power (MAP), and maximal heart rate $\left(\mathrm{HR}_{\max }\right)$ obtained during maximal and incremental exercise were similar in both black Africans and Caucasians. The mean blood lactate concentration obtained 3 min after the end of the maximal exercise test was lower in black Africans than in Caucasians $(p<0.05)$ (Table 1).

\section{Force-velocity exercise test performance}

Blood lactate concentration, heart rate, and skin temperature. The blood lactate concentration was similar at rest $\left(\mathrm{R}_{0}\right)$ in black Africans and Caucasians before the fv exercise test. However, during the test the blood lactate concentration was significantly higher in Caucasians than in black Africans at $4 \mathrm{~kg}(p<0.05), 6 \mathrm{~kg}, \mathrm{~F}_{\text {Pmax }}$, and $\mathrm{F}_{\text {pmax }}+$ $1 \mathrm{~kg}(p<0.05)$, (Fig. 1a). Resting HR $\left(\mathrm{R}_{0}\right)$ was also similar for black Africans and Caucasians. During the fv exercise test, peak HR was lower in black Africans than in Caucasians at the common loads of $2 \mathrm{~kg}(p<0.01), 4 \mathrm{~kg}(p$ $<0.01)$, and $6 \mathrm{~kg}(p<0.05)$. For $\mathrm{F}_{\text {pmax }}$ and $\mathrm{F}_{\text {pmax }}+1 \mathrm{~kg}$, no 


\section{A. TEMFEMO et al.}

Table 1. Anthropometric characteristics [age, height $(\mathrm{Ht})$, body mass $(\mathrm{BM})$, percentage body fat $(\% \mathrm{BF})$, lean body mass (LBM), body mass index (BMI), lean leg volume (LLV), skinfold thickness of rectus femoris (RF), vatus lateralis (VL), and vastus medialis (VM)] and aerobic fitness during the maximal exercise test [maximal oxygen uptake ( $\left.\dot{\mathrm{VO}}_{2 \text { max }}\right)$, maximal aerobic power (MAP), maximal heart rate $\left(\mathrm{HR}_{\max }\right)$, and blood lactate concentration] in black Africans and Caucasians $\left({ }^{*} p<0.05\right)$. Values are expressed as means \pm SD.

\begin{tabular}{|c|c|c|}
\hline & Black Africans & Caucasians \\
\hline Age (years) & $24.2 \pm 2.3$ & $24.6 \pm 3.2$ \\
\hline $\mathrm{Ht}(\mathrm{cm})$ & $181.7 \pm 5.4$ & $179.9 \pm 5.7$ \\
\hline $\mathrm{BM}(\mathrm{kg})$ & $77.4 \pm 4.7$ & $78.1 \pm 4.6$ \\
\hline$\% B F$ & $9.5 \pm 2.3$ & $11.4 \pm 2.9$ \\
\hline LBM (kg) & $70.1 \pm 3.2$ & $69.2 \pm 3.5$ \\
\hline BMI (kg) & $23.5 \pm 1.2$ & $24.2 \pm 1.3$ \\
\hline LLV (I) & $7.2 \pm 0.8$ & $7.4 \pm 0.6$ \\
\hline $\mathrm{RF}_{\text {Skinfold thickness }}(\mathrm{mm})$ & $8.6 \pm 3.5$ & $8.8 \pm 3.2$ \\
\hline $\mathrm{VL}_{\text {Skinfold thickness }}(\mathrm{mm})$ & $9.1 \pm 2.9$ & $8.9 \pm 3.2$ \\
\hline $\mathrm{VM}_{\text {Skinfold thickness }}(\mathrm{mm})$ & $9.1 \pm 2.7$ & $8.9 \pm 2.9$ \\
\hline$\dot{\mathrm{V}} \mathrm{O}_{2 \max }\left(\mathrm{ml} \mathrm{kg}^{-1} \mathrm{~min}^{-1}\right)$ & $54.3 \pm 2.6$ & $56.0 \pm 3.7$ \\
\hline MAP (W) & $290.0 \pm 25.9$ & $286.7 \pm 21.8$ \\
\hline HR (beats $\min ^{-1}$ ) & $178 \pm 6$ & $180 \pm 7$ \\
\hline Blood lactate $\left(\mathrm{mmol} \digamma^{-1}\right)$ & $11.8 \pm 1.9$ & $13.8 \pm 2.2^{*}$ \\
\hline
\end{tabular}

significant difference in peak HR was observed between black Africans and Caucasians (Fig. 1b). Also, a similar percentage of peak $\mathrm{HR}\left(\right.$ at $\mathrm{F}_{\mathrm{Pmax}}$ ) expressed as the percentage of the maximal HR obtained during the maximal exercise test (which was considered as $100 \%$ for each subject) was also found for both black African (82\%) and Caucasian (85\%) subjects. No significant differences between black Africans and Caucasians in terms of peak $\mathrm{T}_{\text {sk }}$ were observed at rest $\left(\mathrm{R}_{0}\right)$ or at all loads during the fv exercise test (Fig. 1c).

Power output and RMS amplitude. No significant difference between black Africans and Caucasians was observed in terms of absolute PO (Fig. 2a) or PO/LLV (Fig. $2 b$ ) at all loads during the fv exercise test. Similar RMS changes and absolute values were observed for the RF (Fig. 3a), VL (Fig. 3b), VM (Fig. 3c), and quadriceps muscle (Fig. 3d) in both black Africans and Caucasians. RMS values (expressed as a percentage of values measured during the first sprint [2 kg], which was considered as $100 \%$ for each group of subjects during the fv exercise test) were also similar in black Africans and Caucasians for the RF (Fig. 4a), VL (Fig. 4b), VM (Fig. 4c), and quadriceps muscle (Fig. 4d). There was also no significant difference in Quad RMS (expressed as a percentage of values measured during the first sprint $[2 \mathrm{~kg}]$, which was considered as $100 \%$ for each group of subjects during the fv exercise test) per unit of LLV (Fig. 5).

\section{DISCUSSION}

In this preliminary study, black African and Caucasian athletesshowed no significant differences in absolute
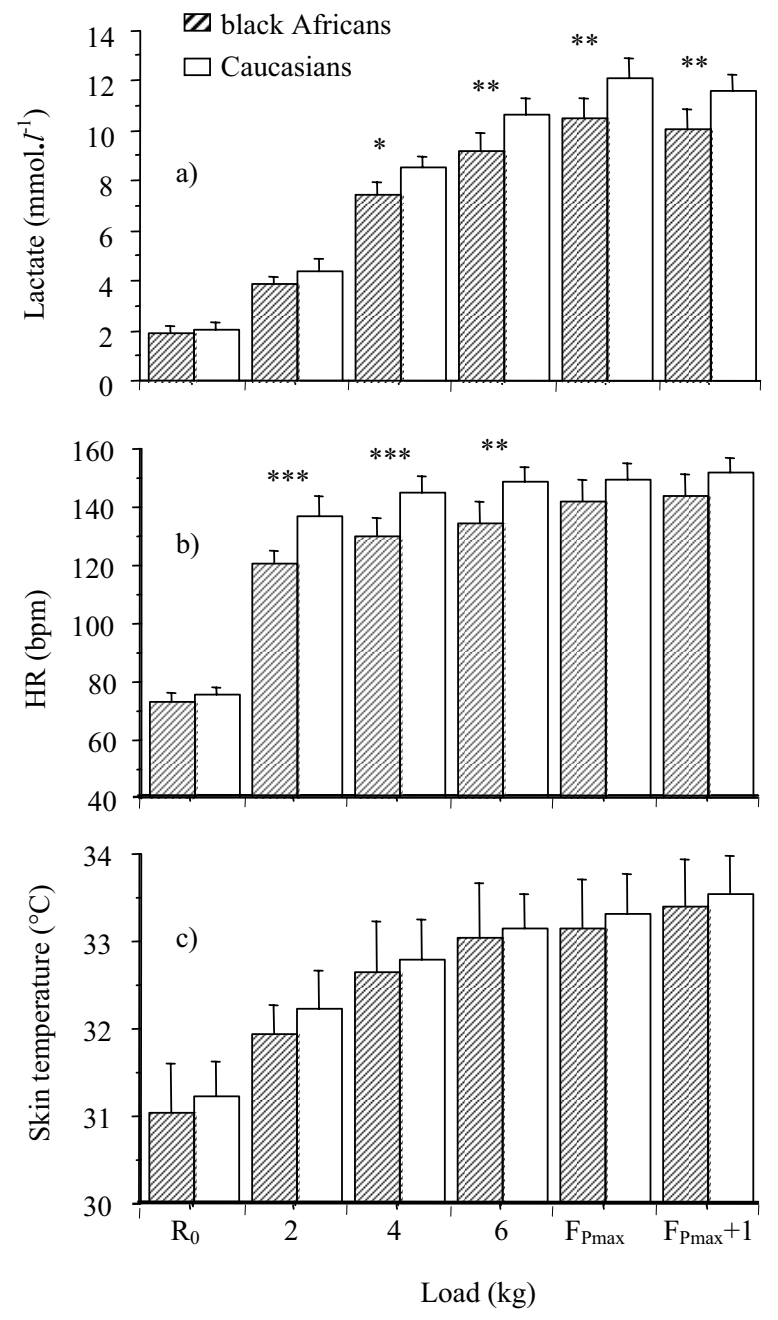

Fig. 1. Blood lactate concentration (a), heart rate (b), and skin temperature (c) in black Africans and Caucasians during the $\mathrm{fv}$ exercise test at rest $\left(\mathrm{R}_{0}\right)$, at the common loads $(2,4$, and 6 $\mathrm{kg}$ ), and at the load corresponding to the peak power output $\left(\mathrm{F}_{\mathrm{Pmax}}\right)$ and the following load $\left(\mathrm{F}_{\mathrm{P} \max }+1 \mathrm{~kg}\right),\left({ }^{* *} p<0.01 ;{ }^{*} p<\right.$ $0.05)$. Values are expressed as means \pm SD.

power output or quadriceps muscle activity during the force-velocity exercise test, despite a higher blood lactate concentration in Caucasians. Even though the number of subjects is small, these results suggest that black African and Caucasian athletes with similar stature, body mass, and maximal oxygen consumption also have similar absolute power outputs and quadriceps muscle activity during brief, intense intermittent exercise performed on a cycloergometer.

In this study, we used the early definition of Vandewalle et al. to calculate power output [29] (i.e., the product of braking force and peak velocity) without taking into account flywheel inertia. Under these conditions, the power output values obtained are underestimates [18]. However, since the calculation of power output was the same for the two groups studied, the power output values obtained represent a valid index for investigating differences between 
black and Caucasian subjects. Furthermore, given that the order of testing was randomized, the tests were performed at the same time of day, and all subjects were familiarized with the fv test before experimentation the performancerelated and metabolic responses obtained cannot be attributed to the effect of day-to-day variation or learning. Moreover, to better determine the power output value at the end of the test, the braking force was increased by only $1 \mathrm{~kg}$. To minimize the potential effects of body movements and oscillations on the power output data obtained, the test was performed in a sitting position for the sprints and all the recovery periods. The feet were fixed to the pedals with toeclips, and the subjects remained seated and kept their hands on the ergometer handlebar throughout the test.

Our present results obtained confirm those of previous reports [20,21], showing a marked blood lactate increase (Fig. 1a) during the fv exercise test. However, despite a similar resting blood lactate concentration and no significant difference in absolute power output, Caucasians had a significantly higher blood lactate concentration than black Africans during the fv exercise test from $4 \mathrm{~kg}$ to $\mathrm{F}_{\text {Pmax }}+1 \mathrm{~kg}$. Lower blood lactate accumulation in black Africans (compared with Caucasians) has previously been reported during intense, continuous exercise [4, 31]. However, this is the first time that this result has been reported for an intermittent sprint exercise. In the present study, we carefully selected black Africans who lacked the sickle cell trait (SCT), since it has previously been suggested that black subjects carrying SCT accumulate significantly less blood lactate while achieving performance levels similar to those of controls [14]. The observed difference in lactate concentration between black Africans and Caucasians might be explained by the lactate shuttle described by Brooks [7], since it was reported that black subjects had a higher proportion of type IIa fibres than Caucasians [1]. In fact, according to Brooks [7] the lactate produced by the recruitment of type IIb fibres with high glycolytic activity and lactate dehydrogenase isoenzyme is transported into type IIa or I fibres, which contain a greater fraction of lactate dehydrogenase and mitochondria, where it is oxidized. Based on these observations, our finding that black Africans have accumulated less blood lactate during intense, intermittent exercise (despite a lack of significant differences in the amount of work performed) is consistent with previous research.

Caucasians also had a significantly higher HR (Fig. 1b) at the first three sprints $(2,4$, and $6 \mathrm{~kg})$ during the fv exercise test as a whole, compared with the black Africans. This difference between the two groups was not apparent at $\mathrm{F}_{\mathrm{Pmax}}$. Marino et al. [19] also observed that Caucasian runners had a significantly higher HR at the beginning of a submaximal run compared with African runners, with this difference disappearing during the 8-km performance run. They also noted that both groups of runners finished
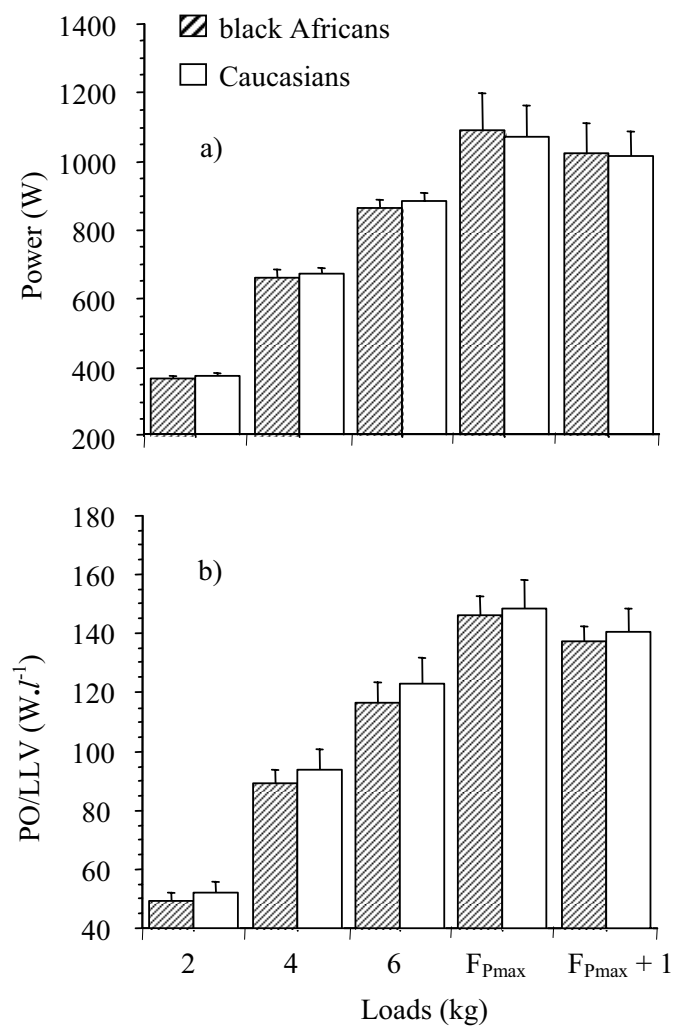

Fig. 2. Power output (W) (a), power output expressed in watts per unit of lean leg volume (b) in black Africans and Caucasians during the $f v$ exercise test. Values are expressed as means $\pm \mathrm{SD}$.

the performance run with identical heart rates, as in the present study.

The present study showed no significant difference in absolute PO (Fig. 2a) between black Africans and Caucasians during the fv exercise test. The lack of difference between black and Caucasian subjects has previously been reported by Boulay et al. [6] during a $\sim 10$-s ergocycle performance test. However, these authors explained the similar performance in black and Caucasian subjects by the lack of familiarity of the black subjects with this specific pedalling task. To our knowledge, direct evidence to support this hypothesis is lacking. In our investigation, each subject was familiarized with the cycling activity. The lack of significant difference in PO in the present study between black Africans and Caucasians might be explained partially by their similar maximal aerobic fitness $\left(\dot{\mathrm{VO}}_{2 \text { max }}, \mathrm{HR}_{\text {max }}\right.$, and MAP) (Table 1) and athletic background. It also might be attributed to the similar proportion of type IIb fibres (fast fibres, which contribute to velocity) or type I, IIa, and IIb fibre areas (which contribute to force generation) in black subjects and Caucasians, also reported by Ama et al. [1]. On the other hand, a high correlation between peak $\mathrm{PO}$ and LBM during the fv exercise test has previously been reported [20]. According to Doré et al. [9], LLV is considered to be the most appropriate 


\section{A. TEMFEMO et al.}
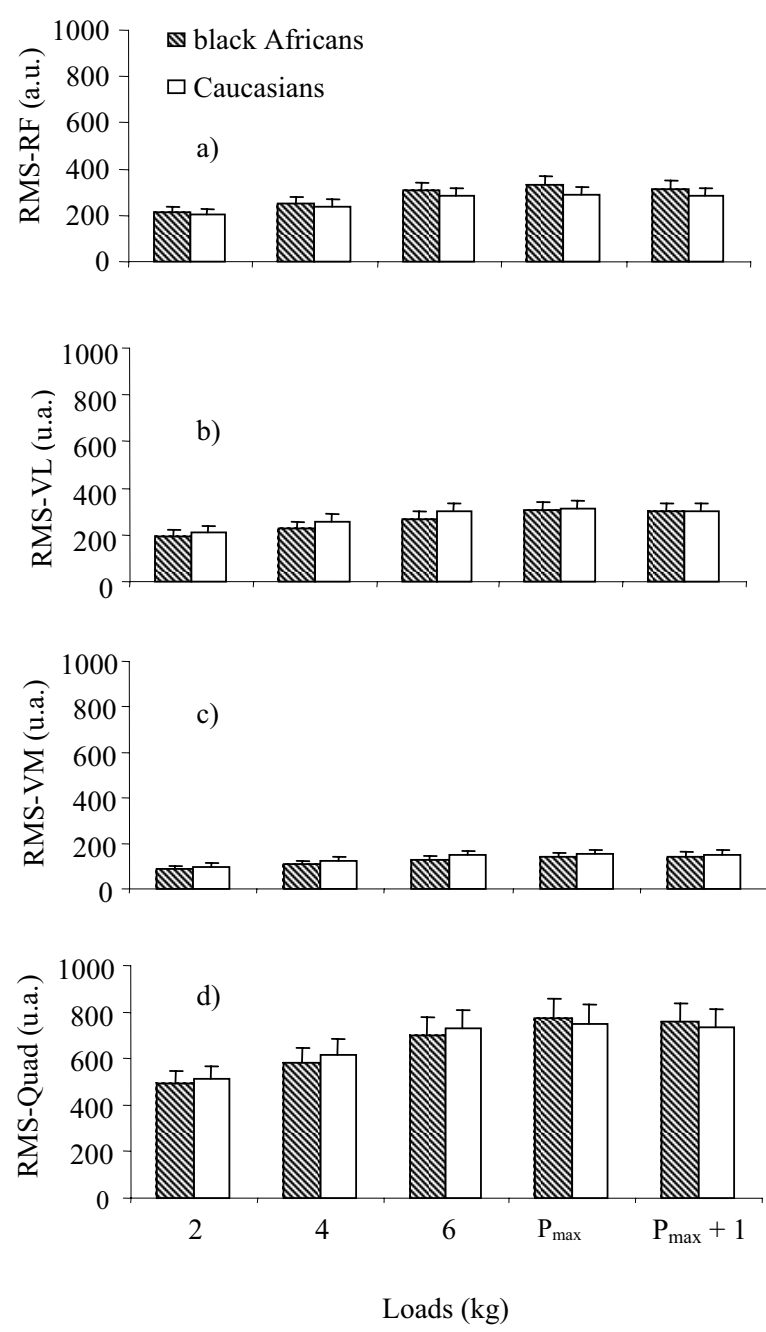

Fig. 3. Absolute values in black Africans and Caucasians during the fv exercise test of RMS of the rectus femoris (RF) (a); vastus lateralis $(\mathrm{VL})(\mathbf{b})$; vastus medialis $(\mathrm{VM})(\mathbf{c})$; and quadriceps (Quad) (d). Values are expressed as means \pm SD.

variable for the standardization of PO in cycling. Since PO/LLV (Fig. 2b) was similar in both groups of subjects, the lack of difference in PO observed between black Africans and Caucasians may also be attributed to their similar LBM and LLV values (Table 1). Thus when matched for aerobic fitness and LBM, black Africans and Caucasians are able to produce similar power outputs during brief, intense, intermittent exercise. However, although the anthropometric data provide a good estimate of leg muscularity, these data do not indicate the proportion of the leg muscle activated during exercise. For this reason, we also assessed the amount of muscular activity during the fv exercise test.

Surface electromyography (SEMG) is widely used to estimate the quadriceps muscle excitation level during explosive, dynamic exercise [13, 22]. We used the RMS of the RF, VL, and VM to determine and compare the quadriceps muscle activity of black Africans and Caucasians
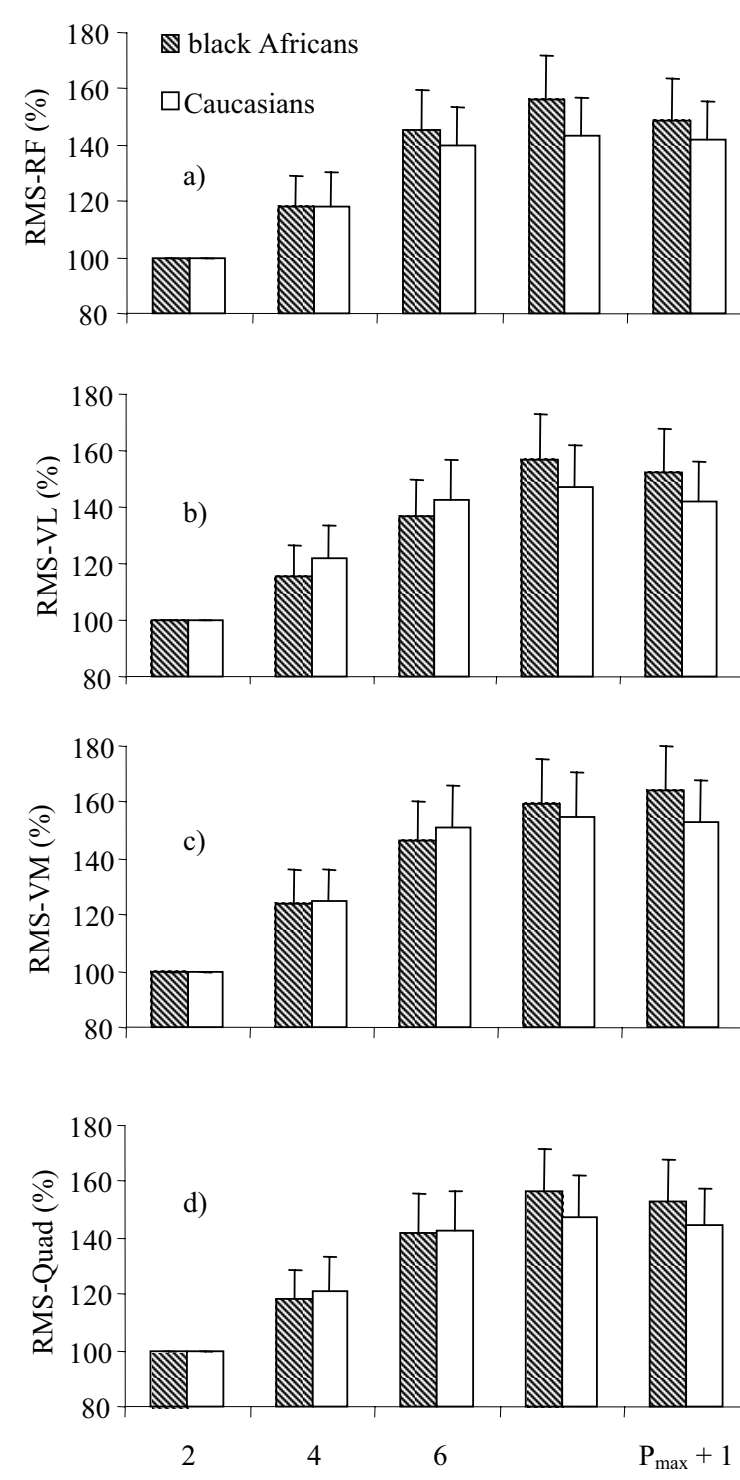

Fig. 4. Relative RMS (\%) in black Africans and Caucasians of the rectus femoris (RF) (a), vastus lateralis $(\mathrm{VL}),(\mathbf{b})$ vastus medialis (VM) (c), and quadriceps (Quad) (d). Values expressed as percentages of values measured at the first sprint ( $2 \mathrm{~kg}$ ), which was considered as $100 \%$ for each subject during the $\mathrm{fv}$ exercise test. Values are expressed as means \pm SD.

during the fv exercise test becausethese muscles are activated during the leg ergocycle exercise and, like the quadriceps, are accessible to SEMG [24, 25]. It should be noted, however, that analyses of SEMG results often reveal high interindividual variation, which is present even among subjects performing exactly the same task [2]. This variation is caused by differences in the thickness and electrical properties of the tissue layers between the surface electrodes and muscles, as well as differences in muscle size, electrode size, and position [27]. In the present study, we tried to minimize the effects of these variables on our results by standardizing the electrode size and position for both groups of subjects. Other factors that may in- 


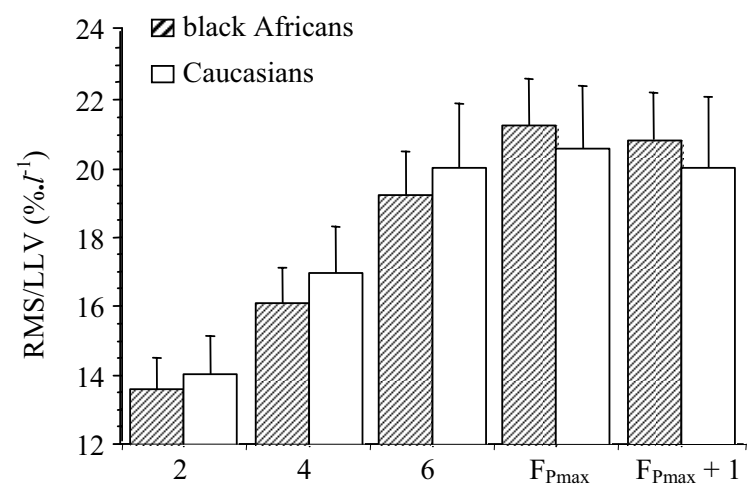

Fig. 5. Quad RMS expressed in percentages per unit of leg muscle volume in black Africans and Caucasians during the fv exercise test. Values are expressed as means $\pm S D$.

fluence the SEMG are temperature [23] and muscle lactate accumulation $[5,17,22]$. There was no significant difference in skin temperature (Fig. 1c) or skinfold thickness (Table 1) between black Africans and Caucasians in the present study. The Caucasians did, however, display significantly greater blood lactate concentrations (Fig. 1a) than the black Africans. Blood lactate accumulation has been associated with an increase in SEMG activity [22], but this relationship does not appear to be causative [5].

The results of the present investigation showed that $\mathrm{PO}$ (Fig. 2a) and absolute RMS of RF, VL, VM, and Quad (Fig. 3, a-d) increased in each group of subjects when the

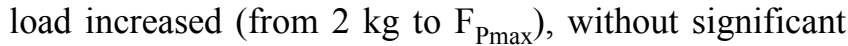
differences between black African and Caucasian athletes. This is consistent with the results of Petrofsky [23] for dynamic contractions and is very likely to be related to the progressive recruitment of motor units (MUs) concomitant with an increase in mechanical power output. It is interesting that Quad RMS seemed to decrease at $\mathrm{F}_{\text {Pmax }}$ $+1 \mathrm{~kg}$ in each group in parallel with the PO decrease. Hunter et al. [15] also reported the use of EMG to track changes in power output. Even when the RMS of RF, VL, VM, and Quad were expressed as percentages (\%) of values measured at the first common load $(2 \mathrm{~kg})$, which was considered $100 \%$ for each subject (Fig. 4, a-d), no intergroup differences were found. There was also no difference between black African and Caucasians athletes in terms of the Quad RMS (\%)/LLV (1) value (Fig. 5). In fact, we had expected a greater value for Quad RMS in black Africans than in Caucasians; it has been reported that black Africans have more type II fibres [1], and RMS has been positively correlated with the proportion of type II muscle fibres [13]. However, our results can possibly be explained by the subjects' similar anthropometric characteristics, aerobic fitness levels, and training backgrounds. Likewise, Duey et al. [10] reported a lack of significant differences in muscle fibre types in African-American and Caucasian men with similar aerobic capacities and training backgrounds.
In conclusion, black African and Caucasian football players (matched for standing height, body mass, lean body mass, lean leg volume, maximal aerobic power, and maximal oxygen uptake) had similar absolute power outputs and quadriceps muscle activity (RMS), but different mean blood lactate concentrations during the fv exercise test performed on a cycloergometer. Based on these preliminary results, we suggest that Caucasians and black Africans with similar stature, aerobic fitness, and training background have similar power output and quadriceps muscle activity during intense, brief, and intermittent exercise test, despite apparent differences in anaerobic metabolism. We conclude that if differences do exist between black African and Caucasians athletes in terms of anaerobic performance and muscular activity, these disparities are weak.

The authors gratefully acknowledge the Corbie's Hospital medical staff for their help and the subjects for their dedicated performance.

\section{REFERENCES}

1. Ama PF, Simoneau JA, Boulay M, Serresse 0 , Thériault G, Bouchard C. Skeletal characteristics in sedentary black and Caucasian males. J Appl Physiol. 1986;61:1758-61

2. Balogh I, Hansson GA, Ohlsson K, Stromberg U, Skerfving S. Interindividual variation of physical load in a work task. Scand J Work Environ Health. 1999;5:57-66.

3. Bilodeau M, Schindler-Ivens S, Williams DM, Chandran R, and Charma SS. EMG frequency content changes with increasing force and during fatigue in the quadriceps femoris muscle of men and women. J Electromyogr Kinesiol. 2003:13:83-92.

4. Bosch AN, Goslin BR, Noakes TD, and Dennis S C. Physiological differences between black and white runners during a treadmill marathon. Eur J Appl Physiol. 1990;61:68-72.

5. Bouissou P, Estrade PY, Goubel F, Guezennec CY, Serrurier B. Surface EMG power spectrum and intramuscular $\mathrm{pH}$ in human vastus lateralis muscle during dynamic exercise. J Appl Physiol. 1989;67:1245-9.

6. Boulay M, Ama PF, Bouchard C. Racial variation in work capacities and powers. Can J Sport Sci. 1988;13:127-35

7. Brooks $G$. The lactate shuttle during exercise and recovery. Med Sci Sports Exerc. 1986;18:360-8

8. Coetzer P, Noakes TD, Sanders B, Lambert MI, Bosch AN, Wiggins T, and Dennis SC. Superior fatigue resistance of elite black South African distance runners. J Appl Physiol. 1993;75:1822-7.

9. Doré E, Bedu M, Franca NM, Diallo O, Duche P, Van Praagh E. Dimensionnenal changes cannot account for all differences in short-term cycling power during growth. Int J Sports Med. 2000;21:360-5.

10. Duey WJ, Bassett DRJ, Torok DJ, Howley ET, Bond V, Mancuso P, Trudell R. Skeletal muscle fibre type and capillary density in college-aged blacks and whites. Ann Hum Biol. 1997;24:323-31.

11. Fernández JR, Heo M, Heymsfield SB, Pierson Jr RN, Pi-Sunyer FX, Wang ZM, Wang J, Hayes M, Allison DB, Gallagher D. Is percent body fat differencially related to BMI in Hispanic-, African, and European-Americans? Am J Clin Nutr. 2003;77:71-5.

12. Gaitanos GC, Williams $C$, Boobis LH, Brooks $S$. Human muscle metabolism during intermittent maximal exercise. J Appl Physiol. 1993;75:712-9.

13. Gerdle B, Karlsson S, Crenshaw AG, Elert J, Fridén J. The influences of muscle fibre proportions and areas upon EMG during maximal dynamic knee extensions. Eur J Appl Physiol. 2000;81:2-10.

14. Gozal D, Thiriet P, Mbala E, Wouassi D, Gelas H, Geyssant A, Lacour JR. Effect of different modalities of exercise and recovery on exercise performance in subject with sickle trait. Med Sci Sports Exerc. 1992;24:1325-31.

15. Hunter AM, St Clair Gibson A, Lambert MI, Nobbs L, and aNoakes TD. Effects of supramaximal exercise on the electromyographic signal. Br J Sports Med. 2004;38:364-5 


\section{A. TEMFEMO et al.}

16. Jones PR, Pearson J. Anthropometric determination of leg fat and muscle plus bone volume in young male and female adults. J Physiol. 1969;204:63-6.

17. Komi PV, Rusko H, Vos J, and Vihko V. Anaerobic performance capacity in athletes. Acta Physiol Scand. 1977;100:107-14.

18. Lakomy H. Measurement of work and power output using friction-load cycle ergometers. Ergonomics. 1986;29:509-17.

19. Marino FE, Lambert MI, and Noakes TD. Superior performance of African runners in warm humid but not in cool environmental conditions. J Appl Physiol. 2004;96:124-30.

20. Mercier B, Mercier J, Granier P, Le Gallais D, Prefaut C. Maximal anaerobic power: relationship to anthropometric characteristics during growth. Int J Sports Med. 1992;13:21-6.

21. Mercier J, Mercier B, and Prefaut C. Blood lactate increase during the forcevelocity exercise test. Int J Sports Med. 1991;12:17-20.

22. Moritani T, Tanaka H, Yoshida T, Ishii C, Yoshida T, Shindo M. Relationship between myoelectric signals and blood lactate during incremental forearm exercise. Am J Phys Med. 1984;63:122-32.

23. Petrofsky JS. Frequency and amplitude analysis of the EMG during exercise on the bicycle ergometer. Eur J Appl Physiol. 1979;41:1-15

24. Pozzo M, Merlo E, Farina D, Antonutto G, Merletti R, and Di Prampero PE.
Muscle-fiber conduction velocity estimated from surface EMG signals during explosive dynamic contractions. Muscle Nerve. 2004;29:823-33.

25. Rabita G, Perot C, and Lensel-Corbeil G. Differential effect of knee extension isometric training on the different muscles of the quadriceps femoris in humans. Eur J Appl Physiol. 2000;83:531-8.

26. Saltin B, Larsen H, Terrados N, Bangsbo J, Bak T, Kim CK, Svedenhag J, Rolf J Aerobic exercise capacity at sea level and at altitude in Kenyan boys, junior and senior runners compared with Scandinavian runners. Scand J Med Sci Sports. 1995;5:209-21.

27. Stegeman DF, Blok JH, Hermens HJ, Roeleveld K. Surface EMG models: properties and applications. J Electromyogr Kinesiol. 2000;10:313-26.

28. Thorstensson A, Grimby G, and Karlsson J. Force-velocity relations and fiber composition in human knee extensor muscles. J Appl Physiol. 1976;40:12-6.

29. Vandewalle H, Pérès G, Heller J, Panel J, Monod H. Force-velocity relationship and maximal power on cycle ergometer. Eur J Appl Physiol. 1987;56:650-6

30. Weiner JS and Lourie JA. Practical human biology. London: Academic Press; 1981. p. 27-52.

31. Weston AR, Karamizrak O, Smith A, Noakes TD, and Myburgh KH. African runners exhibit greater fatigue resistance, lower lactate accumulation, and higher oxidative enzyme activity. J Appl Physiol. 1999;86:915-23. 